\title{
Quantitative Determination of Trypsin Inhibitory Activity in Complex Matrices
}

\author{
Robin E.J. Spelbrink*, Pieter Jan Gerrits, Carina Mooij and Marco L.F. Giuseppin
}

AVEBE U.A., AVEBE-weg 1, 9607 PT, Foxhol, The Netherlands

\begin{abstract}
A quantitative assay using azocasein was developed to measure trypsin inhibitory activity in emulsions and other complex systems that are refractory to analysis. The method was tested for reproducibility on pure protein solutions as well as protein-containing material rich in fats and sugars, with special attention to emulsions. In the clean situation, the overall relative standard deviation was less than $6 \%$ while for the more complex systems it was less than $16 \%$. The procedure proved robust against deliberate variations of temperature, incubation time and substrate concentration.
\end{abstract}

Keywords: Azocasein, Emulsion, Trypsin, Protease Inhibitor, Potato Protease Inhibitor, Trypsin Inhibitory Activity.

\section{INTRODUCTION}

Potato starch manufacture produces a protein-containing waste stream known as potato fruit juice [1]. Thermal coagulation of this material results in a protein-rich material that is commonly used as a feed additive. This thermal treatment however cause protein denaturation, leading to a loss of the potato proteins functional properties. These functional properties and its potential as a medicinal compound (Reviewed in Vlachojanis [2]) have lead several researchers to investigate technologies to obtain potato protein in its native form [3-6]. As a result, native potato protein has recently become commercially available. These protein preparations are used as foaming- [7] and gelling agents [8] and as emulsifiers [9], while still retaining their bioactive properties.

Several recent publications combine the medicinal and functional properties by making use of potato-derived protease inhibitors as bioactive components in emulsions. One prime example is the use of protease inhibitors (PI) in dressings and mayonnaise intended as satiety-enhancing agents [10].

Another example is skin cream, as described in Ruselervon Embden et al. [11] In this case, the emulsion serves to inactivate digestive proteases involved in peri-anal dermatitis [12].

In such applications, a convenient and accurate procedure for determining the level of active component in the final product is desired.

While a variety of assays exist to determine protease inhibitory activity, these procedures are generally unsuited for highly complex and thoroughly emulsified systems. Such assays use chromogenic substrates like $\mathrm{N}_{\alpha}$-Benzoyl-Larginine-p-nitroanilide (L-BAPA) or N $\alpha$-Benzoyl-L-arginine ethyl ester (BAEE) and therefore require a completely solubilised, clear solution for accurate measurements.

*Address correspondence to this author at the AVEBE U.A., AVEBE-weg 1, 9607 PT, Foxhol, The Netherlands; Tel: +31 598662 730; Fax: +31 598 664 273; E-mail: Robin.Spelbrink@ AVEBE.COM
Ruseler-von Embden et al. [11] circumvented this problem by using azocasein as a protease substrate and assessing the loss of proteolytic activity upon incubation in the presence of a PI-rich emulsion. Their method however did not allow for accurate quantification of inhibitory activity.

In this paper we present a procedure for the accurate and reproducible determination of trypsin inhibitory activity in a variety of complex systems using azocasein. In addition to fat-rich PI emulsions, the assay was applied to a sugar-rich PI model system in the form of meringues. Furthermore, several common foodstuffs containing PIs from a variety of sources such as soy, potato and egg were analysed to demonstrate the broad applicability of the method. The differences between the procedure outlined here and previous studies are discussed.

\section{MATERIALS AND METHODOLOGY}

\subsection{Materials}

Tris (hydroxymethyl) aminomethane (Tris) (SigmaAldrich 25,285-9), Azocasein (SigmaAldrich, A2765), Bovine pancreatic trypsin (SigmaAldrich 93610), Potato Protease Inhibitor Isolate (PPI) (Solanic, The Netherlands), L-BAPA (SigmaAldrich B3279), Trichloroacetic acid (TCA) (SigmaAldrich, T9159), $\mathrm{CaCl}_{2} * 2 \mathrm{H}_{2} \mathrm{O}$ (SigmaAldrich, C3881), $\mathrm{NaOH}$ (VWR, 28248.387).

Sample material was either purchased locally or prepared according to methods known in the art.

\subsection{Methods}

\subsubsection{Quantification of Trypsin Inhibitory Activity Using Azocasein}

A $30 \mathrm{~g} / \mathrm{L}$ azocasein stock solution was prepared by dissolving the protein in $100 \mathrm{mM} \mathrm{pH} 8.5$ Tris-buffer containing $5 \mathrm{mM}$ of $\mathrm{CaCl}_{2}$ at $50^{\circ} \mathrm{C}$ and cooling back to $37^{\circ} \mathrm{C}$. Trypsin was accurately weighed for a concentration between 0.3 and $0.4 \mathrm{mg} / \mathrm{mL}$ and dissolved in $1 \mathrm{mM} \mathrm{HCl}$ solution. The trypsin solution was prepared immediately prior to analysis.

Sample material was dispersed in $\mathrm{pH} 3.3$ acetic acid solution. Material that was difficult to disperse was homogenized 
for 10 seconds using a Waring laboratory blender (Waring Commercial, Conneticut, USA).

From the sample material a series of dilutions was prepared in such a way as cause a $\sim 50 \%$ loss of signal upon incubation for the highest sample concentration. From each dilution, $125 \mu \mathrm{L}$ was mixed with $25 \mu \mathrm{L}$ of trypsin stock solution in an eppendorf cup, or with $25 \mu \mathrm{L}$ of demineralised water as a control. Positive and negative controls for the proteolytic reaction used $125 \mu \mathrm{L}$ of demineralised water rather than sample material. To these mixtures $225 \mu \mathrm{L}$ of warm azocasein were added, followed by a 30 minute incubation at $37^{\circ} \mathrm{C}$. The reaction was then quenched by the addition of 150 $\mu \mathrm{L}$ of $15 \% \mathrm{w}: \mathrm{v}$ TCA solution. The order of addition of azocasein was the same as the order of addition of TCA to ensure equal incubation times for all samples.

Non-hydrolysed azocasein and other insolubles were removed by centrifugation at $15,000 \mathrm{~g}$ at $4^{0} \mathrm{C}$ for 10 minutes in a Heraeus Multifuge 1S-R using a Thermo Scientific rotor. $100 \mu \mathrm{L}$ of the supernatants were transferred to a microtiter plate by careful pipetting and supplemented with $100 \mu \mathrm{L}$ of $1.5 \mathrm{M} \mathrm{NaOH}$ solution. The plate was then analysed for absorbence at $450 \mathrm{~nm}$ on a BioRad Model 680 microplate reader.

The absorbences were plotted against the amount of sample material in the plate. The slope of the resulting line was obtained via linear regression using the least squares method and indicates the amount of absorbence lost per quantity of sample material. The positive control, in the absence of sample, indicates the maximum absorbence caused by the known quantity of trypsin. Hence, by dividing the slope by the positive controls' absorbence, the trypsin inhibitory activity expressed as the amount of trypsin inhibited per amount of sample material was obtained.

\subsubsection{Quantification of Trypsin Inhibitory Activity Using $L-B A P A$}

L-BAPA based TIA analysis was performed essentially as described in ISO14902:2001 "Animal Feeding stuffs: Determination of trypsin inhibitor activity of soya products" [13].

\subsubsection{Determination of the $\mathrm{pH}$ Optimum for Tryptic Digestion of Azocasein}

Solutions of $100 \mathrm{mM}$ Tris $/ \mathrm{HCl}$ containing $30 \mathrm{~g}$ azocasein / $\mathrm{L}$ were prepared at different $\mathrm{pHs}$ in the range of $6.5-9.5$ and used as substrate for trypsin in the manner described above. In addition, reaction solutions were insubated overnight with and without enzyme to obtain practical equilibrium situations for the different $\mathrm{pHs}$ in order to correct for different $\mathrm{Km}$ and $\mathrm{kc}$ values according to the procedure of Kasserra and Laidler [14].

\subsubsection{Assay Validation}

For the validation a PI preparation was used as a standard. In addition, two samples of varying matrix composition were used in the validation: an oil-rich dressing prepared with potato PI [10] and a sugar-rich meringue prepared with potato PI. The parameters that were considered in this validation were repeatability, intermediate precision and robustness.

Repeatability represents the similarity in measured values under similar operating conditions. This is expressed as standard deviation within days. Intermediate precision is a measure for laboratory variations such as different days, technicians, equipment and reagents and is expressed as standard deviation between days. In this validation the assay was performed on the samples in triplicate on three consecutive days by three analists.

Robustness was tested by introducing deliberate variation in parameters that were expected to be sensitive: namely incubation time, incubation temperature and substrate concentration. Incubation time was varied from 25 up to 35 minutes. Temperatures between $35^{\circ} \mathrm{C}$ and $40^{\circ} \mathrm{C}$ were tested. The azocasein concentration was varied from 15 to $60 \mathrm{~g} / \mathrm{L}$.

\section{RESULTS}

Increasing the amount of enzyme lead to an increase in the absorbence at $450 \mathrm{~nm}$ in a linear manner for concentrations up to $0.015 \mathrm{mg} / \mathrm{mL}$ (Fig. 1).

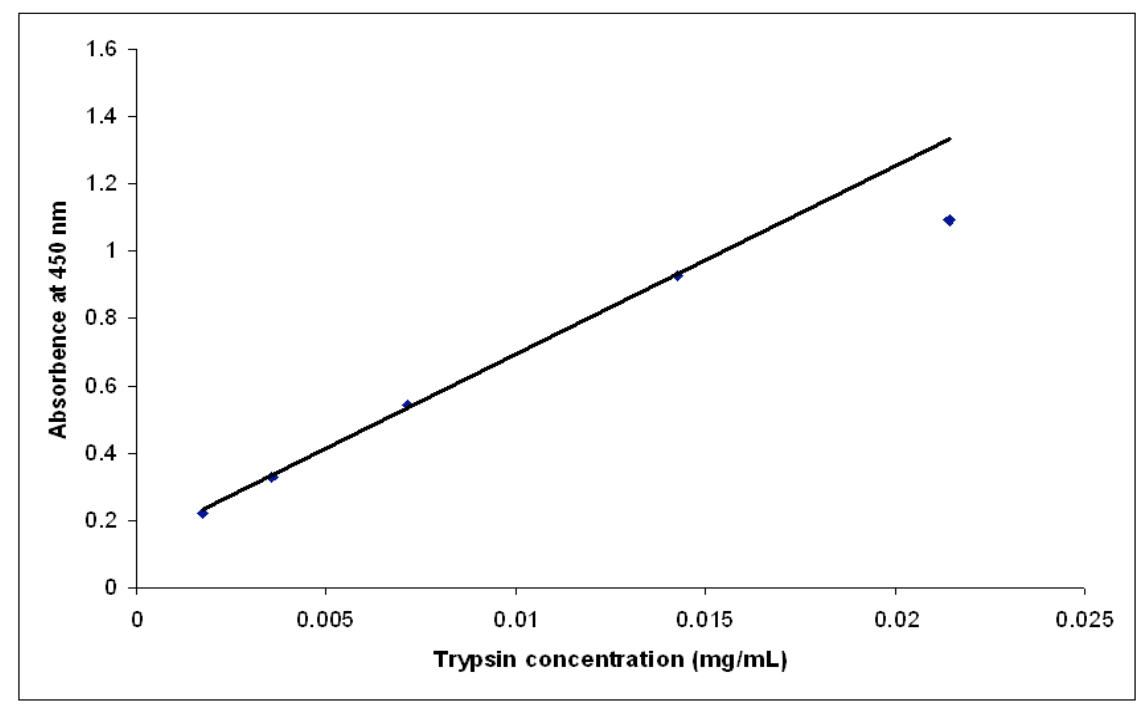

Fig. (1). Absorbence at $450 \mathrm{~nm}$ increases linearly with trypsin concentration up to $0.015 \mathrm{mg} / \mathrm{mL}$. 


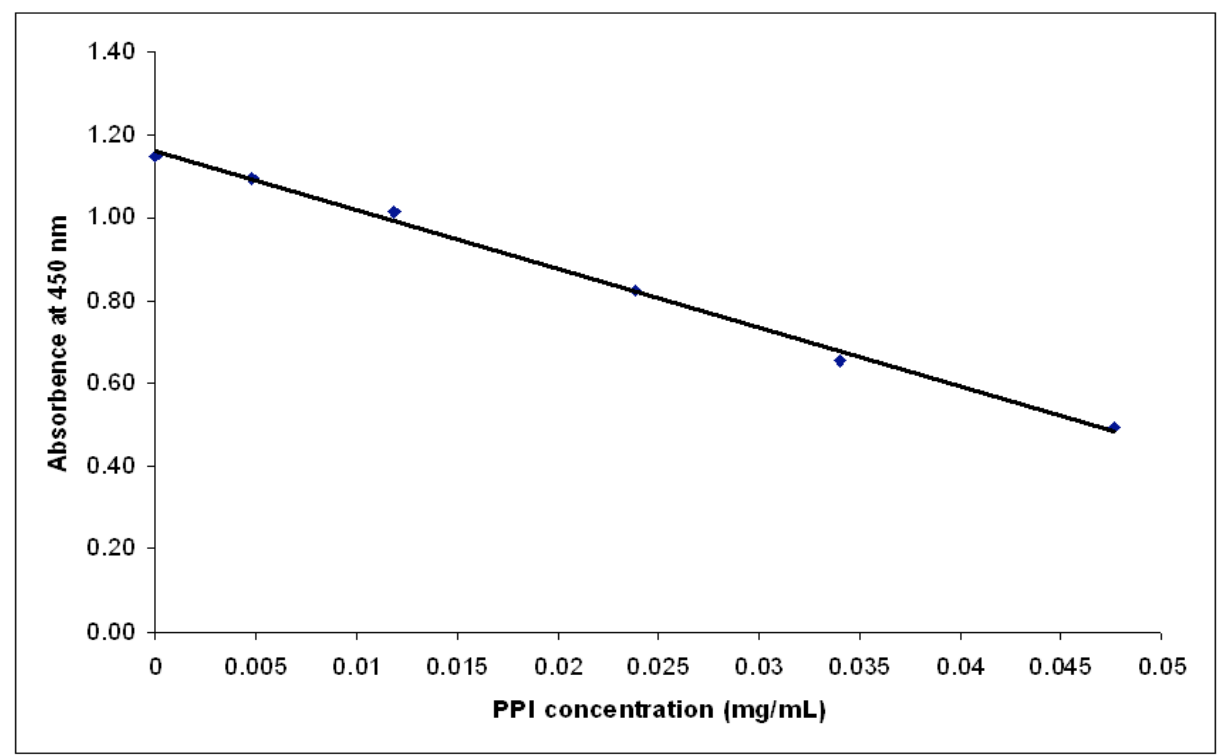

Fig. (2). Loss of tryptic activity upon addition of increasing quantities of potato protease inhibitor.

Similarly, at a constant enzyme concentration, adding known quantities of potato protein inhibitor results in a loss of absorbence (Fig. 2).

If both the quantity of trypsin in the incubation and the amount of sample material that is introduced are known, the amount of trypsin that is inactivated by a certain quantity of sample can be calculated according to the following formula:

$$
\mathrm{IA}=- \text { Slope } * \text { QTA / }(\mathrm{PC}-\mathrm{NC})
$$

Where IA = Inhibition activity

Slope $=$ Slope of A450 against the quantity of sample material in the assay

QTA = Quantity of Trypsin in the Assay

$\mathrm{PC}=$ Positive control, A450 without inhibitor present

$\mathrm{NC}=$ Negative control, A450 without enzyme present

Two factors were found to be of critical importance in this procedure; the assay buffer needs to be of sufficient strength to prevent a $\mathrm{pH}$ shift in the reaction mixture and the trypsin solution must be freshly prepared to avoid autoproteolytic breakdown.

Trypsin acting on azocasein was found to have a $\mathrm{pH}$ optimum of 8.5 (data not shown). Hence, this value rather than the more typical $\mathrm{pH}$ of 8.2 was used.

Changing the incubation temperatures by up to 3 degrees did not influence the result, nor did changing the incubation time by 5 minutes. Varying the substrate concentration like- wise did not effect a change in the obtained inhibition value (data not shown).

To assess the methods reproducibility on model samples of different composition, the assay was performed in triplicate two times per day for 3 days. In addition, the same samples were analysed in triplicate by 3 different analysts. These model samples consisted of a single pure protein preparation, a sugar-rich meringue and a fat-rich dressing (Table 1).

Repeatability, or intra-assay precision, was expressed as relative standard deviation within days $\left(=\mathrm{RSD}_{\text {within day }}\right)$ while intermediate precision was expressed as relative standard deviation between days $\left(=\mathrm{RSD}_{\text {between days }}\right)$. Generated data was, at the same time, used to determine the overall relative standard deviation and the relative standard deviation for a duplicate measurement at a random single day $\left(\mathrm{RSD}_{\text {overall }}\right.$ and $\left.\mathrm{RSD}_{\text {duplicate }}\right)$

Different analysts obtained highly similar values for each preparation.

The assay was deployed in the analysis of food products that were expected to contain trypsin inhibitory activity (Table 2).

A similar, though much more extensive list was previously reported by Doell et al. [15]. As a general rule the assay presented here reports similar trends. Potato, soy and egg-derived products all rank highly in Doell et al.'s table as well as in ours.

Table 1. Repeatability and Intermediate Precision of TIA Assay

\begin{tabular}{|c|c|c|c|c|}
\hline Sample description & Average activity $^{\mathbf{2}}$ & RSD $_{\text {within day }}$ & RSD $_{\text {between days }}$ & RSD $_{\text {overall }}$ \\
\hline \hline PPI & 214 & $2.33 \%$ & $5.54 \%$ & $5.40 \%$ \\
\hline Meringue & 14.8 & $3.30 \%$ & $2.13 \%$ & $3.79 \%$ \\
\hline Dressing & 1.23 & $13.2 \%$ & $3.23 \%$ & $13.5 \%$ \\
\hline
\end{tabular}

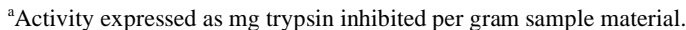


Mayonnaise that was purchased locally contained less TIA than freshly prepared mayonnaise. However, freshly prepared meringues hardly differed from store-bought meringues.

Table 2. TIA Values in Several Foodstuffs Expressed as mg Trypsin Inhibited Per Gram of Product

\begin{tabular}{|c|c|}
\hline Sample & TIA (mg trypsin/g product) \\
\hline Dressing & 0.05 \\
\hline Mayonnaise 1 & 0.12 \\
\hline Mayonnaise 2 & 0.14 \\
\hline Mayonnaise 3 & 0.07 \\
\hline Mayonnaise, fresh & 1.1 \\
\hline Chewy sweets, egg protein-based & 1.5 \\
\hline Soy milk & 0.48 \\
\hline Soy drink yoghurt 1 & 0.04 \\
\hline Soy Yoghurt 1 & 0.10 \\
\hline Soy burger (inside, lyophilised) & 0.46 \\
\hline Soy Oil & 0.54 \\
\hline Soy Yoghurt 2 & 0.06 \\
\hline Soy Drink & 0.26 \\
\hline Soy Drink Yoghurt 2 & 0.02 \\
\hline Icecream (Milk-based) & 2.05 \\
\hline Potato protease inhibitor isolate & 264 \\
\hline Egg protein powder & 151 \\
\hline Meringue, Potato protein based & 13.2 \\
\hline Meringue, egg protein based & 4.7 \\
\hline Meringue & 3.3 \\
\hline Paté & 0.4 \\
\hline Sausage & 0.0 \\
\hline Sausage, pea protein based & 0.8 \\
\hline Salami sausage & 0.1 \\
\hline
\end{tabular}

Milk-based icecream was found to be fairly high in TIA, as was egg-based chewy candy.

The values reported by the present assay differ from those that are obtained by the procedure outlined in ISO14902:2001 [13] which uses the synthetic L-BAPA substrate. This procedure yields inhibition activity of $800-1100$ $\mathrm{mg}$ trypsin inhibited per gram PPI. The PPI values in Tables $\mathbf{1}$ and $\mathbf{2}$ were obtained on different preparations. Values obtained using the azocasein protein are typically in the 220300 range for different PPI preparations.

\section{DISCUSSION AND CONCLUSION}

The results show that the amount of A450 is linear with the amount of trypsin in the assay, a requisite for the quanti- tative determination of TIA levels. Furthermore, exposing the trypsin-azocasein system to increasing amounts of protease inhibitor reduces the A450, again in a linear manner. These results demonstrate that quantification of protease inhibitory activity via this method is feasible. The data are expressed as amount of protease inhibited per amount of sample material. As Kakade et al. [16] and Smith et al. [17] pointed out, such values prevent the confusion that arises from using arbitrary values and allow the amount of inhibitory activity to be more easily appreciated by non-analists.

The procedure that is described above differs in several aspects from previous methods. Because the current method focuses on potato protease inhibitors rather than soy-based material, sample extraction is performed at low $\mathrm{pH}$ instead of neutral or slightly alkaline $\mathrm{pH}$. PPI is highly soluble under these conditions. While alkaline conditions like those used by Kakade et al. [18], Stauffer [19] and Smith et al. [17] also favour PPI solubility, these were avoided to prevent oil and fat hydrolysis as free fatty acids may also inhibit trypsin.

The major difference however is the use of azocasein as a substrate rather than the artificial chromogenic substrates used in most studies that were published after Kakade et al's, [18].

Kakade et al. reported differences between inhibitory values obtained by the BAEE substrate and casein for soy PI, but preferred BAEE over casein because the latter did not conform to a linear dose-response relationship. We found similar although more pronounced differences between LBAPA and azocasein for potato PI, but in both cases linear dose-response relationships were obtained.

Several authors have observed that varying the substrate results in different inhibition activities in the same proteasePI system. Nielsen and Liener observed that endogenous proteases from Phaseolus vulgaris responded differently to a variety of inhibitors when either L-BAPA or azocasein or endogenous storage proteins were offered as substrate [20]. Generally, synthetic substrates yield higher inhibitory activities then natural proteins [21] Fritz et al. [22] explain this phenomenon by suggesting that the larger, natural substrates are more difficult to displace from the active site to form the enzyme-inhibitor complex. If correct, this suggests that while the use of synthetic substrates is a more accurate means of determining the inhibitor content of materials [18], the use of natural substrates will yield a value that has more physiological relevance.

Azocasein may be considered inconvenient because of the necessity for acidic precipitation, but because it is an actual protein rather than a synthetic model substrate we expect it to better represent physiological processes. For this reason, we attach more value to the results obtained by the azocasein-based method than by the L-BAPA based methods.

Furthermore, azocasein is susceptible to breakdown by a variety of proteases, which allows the current assay to be conveniently adepted to work with other proteases or mixtures thereof. Indeed, Ruseler-von Embden et al. [11] used an azocasein based, though non-quantitative, assay in their studies on treatment of dermatitis that is caused by a complex mixture of proteases. This demonstrates the suitability of azocasein for such purposes. 
Another advantage of the current assay is its robustness in the variety of sample matrices it can handle. The use of chromogenic substrates necessitates a clear solution while the TCA precipitation and centrifugation steps allow the azocasein-based assay to handle thoroughly emulsified systems like dressings and mayonnaise. A series of validation experiments revealed that repeating the experiment yields values that differ by less than $6 \%$ for relatively clean systems such as water-soluble protein or protein-sugar systems and by less than $15 \%$ for protein-fat emulsions. This should be sufficient to allow for dosage control in final products that use PPI as a bioactive ingredient.

Smith et al. reported difficulties in measuring certain samples. Specifically, these authors encountered difficulties in obtaining linear dose-response relationships between residual trypsin activity and the added amount of sample, stating that "the main problem in the determination of TI lies in the apparent deviation from linearity of response." This problem was most pronounced for dairy-based samples. The azocasein-based assay presented here has no such problems. In our experience, deviations of linearity result from shifts in $\mathrm{pH}$ upon adding the sample. Increasing the buffer strength from $50 \mathrm{mM}$ Tris, which is common in the literature, to 100 $\mathrm{mM}$ adequately remedied the problem.

The azocasein assay was tested on a variety of common emulsions and food systems in a manner similar to, but much less elaborate than Doell et al. [15] Nevertheless, our results are in agreement with theirs, indicating that potato, eggs and soy are all major contributors to the total intake of proteolytic trypsin inhibitory activity.

A strong difference was found between mayonnaise prepared in-house and store-bought mayonnaise. Presumably this represents a difference in thermal treatment.

The method that is described here allows for the accurate quantification of TIA from a broad variety of sample matrices.

\section{ACKNOWLEDGEMENT}

Non declared.

\section{CONFLICT OF INTEREST}

Non declared.

\section{REFERENCES}

[1] Knorr D, Kohler GO, Betschart AA. Potato protein concentrates: the influence of various methods of recovery upon yield, compositional and functional characteristics. J Food Process Preserv 1977; 1: 235-47.

[2] Vlachojannis JE, Cameron M, Chrubasik S. Medicinal use of potato-derived products: a systematic review. Phytother Res 2010; 24(2): 159-62.
[3] Edens L, van der Lee JAB, Plijter JJ, inventors; Gist-Brocades B.V, assignee. Novel Food Compositions. WIPO Patent Application WO/1997/042834. 1997 May.

[4] Giuseppin MLF, Laus MC, van der Sluis C, inventors; AVEBE UA, assignee. Native Potato Protein Isolates. United States Patent Application 20100040591. 2007 April.

[5] Hansen MB, Lihme AOF, inventors; Upfront Chromatography A/S assignee. Method for high-throughput volumes in the fractionation of bio-molecules by chromatographic systems 2004 .

[6] Streatkvern KO, Schwarz JG, Wiesenborn DP, Zafirakos E, Lihme A. Expanded bed adsorption for recovery of patatin from crude potato juice. Bioseparation 1999; 7: 333-45.

[7] van Koningsveld GA, Walstra P, Gruppen H, Wijngaards G, van Boekel MASJ, Voragen AGJ. Formation and stability of foams made with various potato protein preparations. J Agri Food Chem 2002; 50: 7651-9.

[8] Creusot N, Wierenga PA, Laus MC, Giuseppin ML, Gruppen H. Rheological properties of patatin gels compared with betalactoglobulin, ovalbumin and glycinin. J Sci Food Agric 2010; 91(2): 253-61.

[9] Ralet M-C, Guehuen J. Fractionation of potato proteins: solubility, thermal coagulation and emulsifying properties. LebensmittelWissenshaft Und Tech 2000; 33: 380-7.

[10] van Nieuwenhuizen N, Giuseppin MLF, Tromp RH, inventors; AVEBE UA, assignee.. Condiment. WIPO Patent Application WO/2010/098663. 2010 September

[11] Ruseler-van Embden JGH, van Lieshout LMC, Smits SA, van Kessel I, Laman JD. Potato tuber proteins efficiently inhibit human feacal proteolytic activity: implication for treatment of peri-anal dermatitis. Eur J Clin Invest 2004; 34: 303-11.

[12] Ruseler-van Embden JGH, van Lieshout LMC, Laman JD. Inventors; Erasmus University Rotterdam, assignee. Method and means for preventing or treating inflammation or pruritis. WIPO Patent Application WO/1999/059623. 1999 May.

[13] Animal Feed Stuffs - Determination of trypsin inhibitor activity of soya products. ISO 14902: 2001(E)2001.

[14] Kasserra HP, Laidler KJ. pH effects in trypsin catalysis. Can J Chem 1969;47: 4021-9.

[15] Doell BE, Ebden CJ, Smith CA. Trypsin inhibitor activity of conventional foods which are part of the british diet and some soya products. Qual Plant Plant Foods Hum Nutr 1982; 31: 139-50.

[16] Kakade ML, Rackis. JJ, McGhee JE, Puski G. Determination of trypsin inhibitor activity of soy products: a collaborative anaylsis of an improved procedure. Am Assoc Cereal Chem 1974; 51: 376-82.

[17] Smith C, van Megen W, Twaalfhoven L, Hitchcock C. The determination of trypsin inhibitor levels in foodstuffs. J Sci Food Agric 1980; 31: 341-50.

[18] Kakade ML, Simons N, Liener IE. An evaluation of natural vs. synthetic substrates for measuring the antitryptic activity of soybean samples. Cereal Chem 1969; 46: 518-26.

[19] Stauffer CE. Measuring trypsin inhibitor in soy meal: suggested improvements in the standard method. Cereal Chem 1990; 67(3): 296-392.

[20] Nielsen SS, Liener IE. Degradation of the major storage protein of phaseolus vulgaris during germination: role of endogenous proteases and protease inhibitors. Plant Physiol 1984; 74: 494-8.

[21] Laskowski M, Laskowski MJ. Naturally occuring trypsin inhibitors. Adv Protein Chem 1954; 9: 203-42.

[22] Fritz H, Trautschold I, Haendle H, Werle E. Chemistry and biochemistry of proteinase inhibitors from mammalian tissue. Ann NY Acad Sci 1968; 146: 400-12.

(C) Spelbrink et al.; Licensee Bentham Open.

This is an open access article licensed under the terms of the Creative Commons Attribution Non-Commercial License (http://creativecommons.org/licenses/by-nc/3.0/) which permits unrestricted, non-commercial use, distribution and reproduction in any medium, provided the work is properly cited. 